\title{
Monitoring of invasive Aspergillosis antifungal therapy by quantitative reverse transcriptase real-time polymerase chain reaction (qRT- PCR)
}

Hossein Khodadadi $^{* 1}$, Ladan Karimi², Keyvan Pakshir ${ }^{1}$, Kamiar Zomorodian ${ }^{1}$

${ }^{1}$ Department of Medical Parasitology and Mycology, Shiraz University of Medical Sciences, shiraz, Iran ${ }^{2}$ Clinical Laboratory of Shahid Beheshti Hospital, Social Security Organization, shiraz, Iran

\section{Objectives: Assessment of antifungal} therapeutic efficacy of invasive aspergillosis (IA) is essential and reliable methods to quantify response to anti-Aspergillus drugs are desirable. Although serum beta-glucan (BG) and galactomannan (GM) levels were evaluated during antifungal therapy, the levels of these antigens fluctuate irregularly and do not show early therapeutic response correctly. Recently some efforts focused on detection and quantification of Aspergillus RNA in serum as a biomarker. We developed a quantitative reverse transcriptase real-time polymerase chain reaction (qRT-PCR) for following up responses to antifungals in IA patients.

Methods: Total RNA was extracted from 188 blood samples of 36 patients with proven or probable IA during their antifungal therapy regimen. The loads of Aspergillus 18S rRNA were quantified by a newly designed panAspergillus qRT-PCR. GM levels in serum were measured simultaneously and clinical outcome were assessed. The correlation between the changes of circulating Aspergillus RNA load and serum GM levels and the clinical outcome were statistically compared.

\begin{tabular}{lccccc}
\hline \multicolumn{5}{c}{$\begin{array}{c}\text { Correlation between Aspergillus RNA load } \\
\text { and 10 weeks outcome }\end{array}$} \\
\hline Clinical outcome & $\begin{array}{l}\text { Increased fungal } \\
\text { RNA load from } \\
\text { week 2 to week 6 } 6\end{array}$ & $\begin{array}{l}\text { Decreased or no } \\
\text { change of fungal RNA } \\
\text { load from week 2 to } \\
\text { week 6 }\end{array}$ & Kappa & Pvalue \\
\hline $\begin{array}{l}\text { Responder } \\
(n=7)\end{array}$ & 2 & 5 & 0.598 & 0.031 \\
\hline $\begin{array}{l}\text { Nonresponder } \\
(n=2)\end{array}$ & 2 & 0 & & \\
\hline
\end{tabular}

Results: Thirty-six patients with newly diagnosed $I A$ and receiving anti-Aspergillus drugs were evaluated weekly for 10 weeks. 34 out of $188(18.1 \%)$ blood samples belonging to 9 patients had positive qRT-PCR results. Aspergillus RNA load decreasing was seen in 7 patients. Fungal RNA decrease began from third week of antifungal therapy initiation. This decrease associated with an excellent response to antifungals. Although changes of blood Aspergillus RNA load correlates with clinical outcome, the fungal RNA load did not show correlation with GM levels.

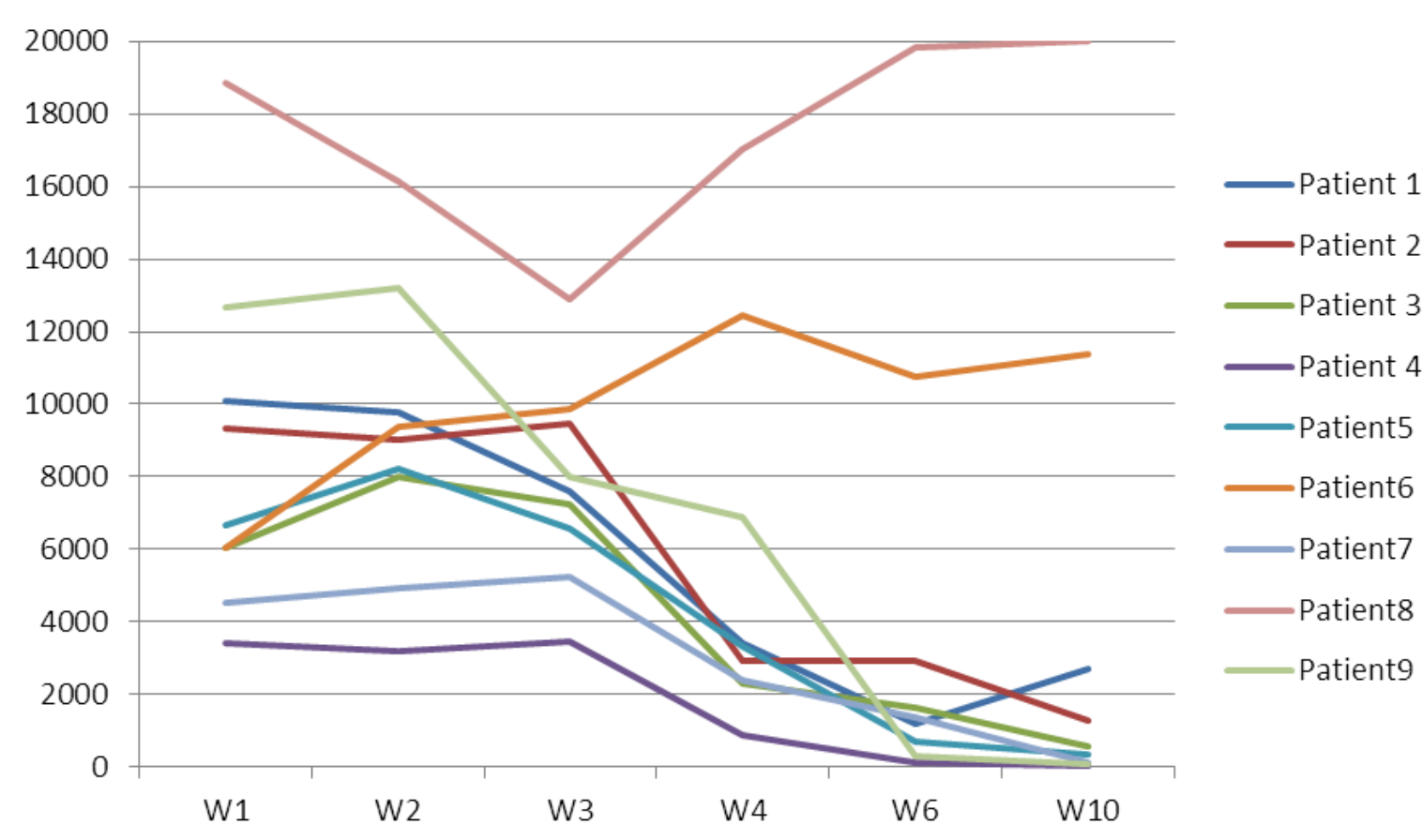

Aspergillus 18SrRNA copy number changes during weekly patients assessment

Conclusions: Changes of blood Aspergillus RNA load during antifungal therapy correlates with final clinical outcome. The measurement of changes of circulating Aspergillus RNA load in combination with other assays may help for monitoring the response to anti-fungal therapy. 